\title{
Liberalización e internacionalización de la agricultura chilena
}

DOI: 10.32870/mycp.v9i27.278

José Jaime López Jiménez*

\section{Introducción}

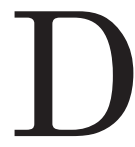
urante las últimas tres décadas la economía chilena en general y la agricultura en particular experimentaron profundos cambios estructurales orientados a su apertura e inserción en el mercado internacional. En una primera etapa, que comprende de 1974 a 1983 , las reformas y ajustes se aplicaron en forma ortodoxa para alcanzar una rápida liberalización y apertura del sector agropecuario. Posteriormente, a partir de la crisis experimentada por la economía chilena en 1984, las políticas se tornaron más heterodoxas, ya que el Estado se vio en la necesidad de recurrir nuevamente a medidas intervencionistas para proteger a sus productores ante las fluctuaciones del mercado internacional.

En los años noventa y en la presente década se mantuvo el modelo de apertura económica, pero procurando cierta equidad social y productiva para el óptimo desarrollo del sector agropecuario, en reconocimiento a la heterogeneidad del campo chileno. Paralelamente, se continuó con medidas de estabilización de precios, de fomento a la competitividad y se reforzó la inserción en los mercados internacionales por medio de acuerdos comerciales mul-

* Profesor-investigador del Departamento de Estudios del Pacífico, Centro Universitario de Ciencias Sociales y Humanidades, Universidad de Guadalajara, y miembro del SNI. tilaterales y, principalmente, de carácter bilateral.

Estos cambios en la política agrícola se han traducido en un gran dinamismo de la producción agropecuaria y del sector agroexportador chileno; los agentes más favorecidos son las empresas exportadoras de frutas, la industria forestal y la agroindustria, particularmente la relacionada con el procesamiento de productos como azúcar, cebada, leche, arroz, uva, carne de cerdo y de aves, jugos y pastas. Con ello, la agricultura chilena experimentó una rápida inserción en el mercado internacional, principalmente de las regiones agrícolas irrigadas y con una adecuada capacidad tecnológica y de gestión.

El presente trabajo consta de dos apartados. En la primera parte se expone de forma breve la situación de la agricultura chilena hasta principios de los años setenta, justo antes de las reformas económicas implementadas por el régimen militar; posteriormente se analiza por etapas la reforma estructural del sector agropecuario chileno, subrayando los cambios esenciales en la política agrícola, los ajustes sobre el modelo que el gobierno tuvo que introducir con el fin de corregir ciertos desequilibrios provocados por factores internos y externos, así como la estrategia de inserción en los mercados internacionales mediante acuerdos comerciales multilaterales y bilaterales. En la segunda parte se evalúan los efectos más relevantes de los cambios 
y ajustes en la estructura de producción agropecuaria y en el sector agroexportador chileno. Finalmente, se formulan algunas reflexiones en relación con la experiencia chilena respecto a la liberalización y apertura de su sector agropecuario.

\section{El sector agropecuario chileno antes de la apertura}

Hasta principios de los años setenta el sector agropecuario chileno se mantuvo inscrito en el modelo de industrialización vía sustitución de importaciones iniciado por este país desde los años treinta. Uno de los efectos de esta estrategia, al igual que en otros países de América Latina, fue el prolongado estancamiento que experimentó la agricultura. Este fenómeno, derivado de las políticas de impulso a la industrialización, originó fuertes distorsiones en la rentabilidad de las actividades agropecuarias y una pérdida de importancia de su participación en el producto nacional y de competitividad en el exterior.

La carencia de esquemas eficientes para la capitalización del sector industrial se combinó con la falta de un sector agrícola más dinámico que pudiera responder a los requerimientos que el mismo desarrollo le imponía. Respecto a la agricultura, la disminución de la inversión pública en el campo provocó, entre otros efectos, un descenso en la producción y una agudización de la migración campo-ciudad, lo que a su vez estimuló el desempleo en las áreas urbanas y la incapacidad de satisfacer la creciente demanda de alimentos (véase Coeymans y Mundlak, 1993). Esta incapacidad del sector agropecuario para satisfacer adecuadamente el suministro de insumos y alimentos ocasionó serios problemas de abastecimiento en los centros urbanos, incidiendo cada vez más en el nivel de vida de la población en general hasta alcanzar niveles críticos a comienzos de la década de los sesenta, situación que sería enfrentada por el gobierno con la aplicación de un programa de reforma agraria y otras medidas de corte intervencionista con el propósito de estimular la producción agropecuaria (cuadro 1).

Para entonces se consideraba al sector agropecuario como el soporte básico para avanzar en el proceso de industrialización, debido a que su estancamiento presionaba al gobierno a un mayor desvío de recursos derivado de las importaciones de alimentos, además de otros efectos sociales como el desempleo urbano y el surgimiento de cinturones de pobreza en la periferia de las ciudades, generados por las oleadas de campesinos. Con la promulgación de la Ley de Reforma Agraria, en 1964, se buscó impulsar las actividades agrícolas al modificarse el régimen de propiedad de la tierra. Esta medida permitió expropiar predios considerados poco productivos y de una superficie mayor de 80 hectáreas de riego. Además, se aplicó un programa integral de transformación y modernización que incluía, entre otras políticas, la operación de planes de fomento para los subsectores forestal, frutícola y ganadero (véase Palma Arancibia, 1993).

En 1970, con el arribo de Salvador Allende a la presidencia se profundizó el programa de reforma agraria al eliminarse las restricciones legales en relación con la superficie mínima de los predios sujetos a expropiación, situación que propició un clima de fuerte inseguridad en el campo. Además de estos cambios en la tenencia de la tierra, se introdujo la política de control sobre los precios agrícolas y se impusieron fuertes restricciones sobre las importaciones agrícolas, derivando todo ello en un mayor desabasto de los principales productos básicos.

MÉXICO YLACUENCADELPACÍFICO vol. 9, núm. 27 / enero - diciembre de 2006 
Análisis

\section{Cuadro 1}

La política agrícola chilena hasta 1973

\begin{tabular}{|c|c|}
\hline Medidas de política más importantes & Instrumentos \\
\hline Distribución de la tierra & Ley de Reforma Agraria \\
\hline Planes de fomento por subsectores & $\begin{array}{l}\text { Plan Frutícola, Plan Ganadero Sur, creación de empresas agroindustriales } \\
\text { verticales, financiamiento público (tasas de interés preferenciales). CORFO, } \\
\text { INDAP. }\end{array}$ \\
\hline $\begin{array}{l}\text { Intervención de mercados } \\
\text { agropecuarios }\end{array}$ & $\begin{array}{l}\text { Fijación de precios agrícolas, control de la producción agrícola, control } \\
\text { de exportaciones e importaciones, exenciones de impuestos y aranceles. } \\
\text { ECA, Banco Central. }\end{array}$ \\
\hline Desarrollo de infraestructura de riego & $\begin{array}{l}\text { Construcción de grandes embalses y redes de riego, incorporación de } 600 \\
\text { mil hectáreas de riego. }\end{array}$ \\
\hline Fomento a la pequeña agricultura & Programas de asistencia técnica y crédito a campesinos. INDAP. \\
\hline Fomento a la innovación tecnológica & $\begin{array}{l}\text { Apoyo a la investigación agropecuaria, financiamiento a las universidades } \\
\text { e institutos tecnológicos. INIA. }\end{array}$ \\
\hline $\begin{array}{l}\text { Fomento a organizaciones de } \\
\text { productores }\end{array}$ & $\begin{array}{l}\text { Apoyo a los sindicatos y organizaciones campesinas, fomento a la actividad } \\
\text { cooperativa. Leyes de fomento cooperativo. }\end{array}$ \\
\hline Participación del sector público & ODEPA, CORA, INDAP, INIA, IER, ICIRA, IDI, etcétera. \\
\hline
\end{tabular}

Fuente: Portilla, 2000.

Pero también hubo cambios significativos en favor de la organización sindical campesina y del movimiento cooperativo en las formas de asignación de los recursos financieros hacia el sector, así como en el desarrollo de la infraestructura agroindustrial. Sin embargo, la crisis generalizada en el plano político y económico terminó por frustrar la incipiente experiencia de modernización de la agricultura que se había iniciado años atrás. De esta forma, previo al arribo del régimen militar de Pinochet en septiembre de 1973, el sector agropecuario chileno se encontraba entre los más regulados y sujetos a controles por parte del gobierno. Además, el programa de reforma agraria había dado como resultado que cerca de la mitad de la tierra agrícola fuera expropiada y que las grandes unidades de producción rural prácticamente desaparecieran, a cambio de dotar de tierra a los campesinos que carecían de la misma.

\section{Primera fase de las reformas, 1974-1983: liberalización y apertura al exterior}

A partir de 1974 la política agropecuaria se orientó a establecer las bases para la aplicación de una nueva estrategia de desarrollo: generar un renovado escenario de confianza entre los productores medianos y grandes, y desarticular el movimiento campesino apoyado por el gobierno de Salvador Allende. En el terreno político, el primer paso consistió en devolver a sus antiguos propietarios las tierras que les habían sido expropiadas con la Reforma Agraria y, en segundo lugar, se estableció una serie de disposiciones legales para debilitar a los sindicatos y organizaciones campesinas, complementadas con una fuerte represión social. Mientras que en el campo económico se impulsó la liberalización comercial y del mercado agropecuario, y se fomentaron las exportaciones agropecuarias (Portilla, 2000). 
Bajo esta nueva estrategia para la liberalización de la agricultura, el gobierno militar suprimió una serie de importantes restricciones sobre la producción agrícola. Las reformas más importantes en esta fase incluyeron la restitución de la tierra a sus antiguos propietarios y un renovado estímulo a la inversión privada en el campo; la disminución de la intervención del sector público en la agricultura; la privatización de los mercados de insumos y de productos; la liberalización del comercio agropecuario y la eliminación de los controles sobre los precios agrícolas (cuadro 2).

Fue así como se devolvió a sus antiguos propietarios la tierra expropiada con la reforma agraria: se suprimió la política de bandas de precios agrícolas — que consistían en un precio mínimo y otro máximo-; el gobierno se retiró de las actividades relacionadas tanto con la comercialización agrícola como con la producción y distribución de insumos agropecuarios; se eliminaron los subsidios a los fertilizantes, el crédito rural, la maquinaria y otros insumos. De igual forma, se modificaron las leyes en materia laboral procurando una mayor flexibilidad en el mercado de trabajo (véanse Venezian y Muchnik, 1995; Portilla, 2000). Para una mejor comprensión de la dimensión y alcance de cada una de las medidas implementadas, a continuación se describe de manera general la forma en que se llevaron a cabo, así como sus resultados.

\section{Cuadro 2}

Principales cambios en la política agrícola chilena entre 1974 y 1983

\begin{tabular}{ll}
\hline Medidas de política más importantes & Instrumentos \\
\hline Fomento de un mercado libre de tierras & $\begin{array}{l}\text { Restitución de tierras expropiadas, distribución de predios indivi- } \\
\text { duales, disposiciones legales que impiden la expropiación de la } \\
\text { tierra. Leyes que disuelven a comunidades indígenas. }\end{array}$ \\
$\begin{array}{ll}\text { Liberalización de mercados agropecuarios } & \text { Se liberan los precios, excepto de remolacha. Bandas de precios } \\
\text { en trigo y oleaginosas se eliminan en 1979. Menor intervención } & \text { en la comercialización: disminuyen apoyos del gobierno; pri- } \\
& \text { vatización de empresas estatales; disminución de aranceles y } \\
\text { fomento a exportaciones no tradicionales. }\end{array}$ \\
$\begin{array}{ll}\text { Financiamiento rural } & \text { Se suprimen programas de redescuento de deudas y créditos } \\
\text { preferenciales. Se establecen tasas de interés de mercado. }\end{array}$ \\
$\begin{array}{l}\text { Reducción de apoyos estatales a nuevas obras. Se fomenta la in- } \\
\text { versión privada en la construcción de infraestructura de riego. }\end{array}$ \\
$\begin{array}{l}\text { Disminuye el financiamiento del gobierno a la investigación } \\
\text { Innovación tecnológica }\end{array}$ \\
$\begin{array}{l}\text { inversión privada. } \\
\text { Política forestal }\end{array}$ \\
$\begin{array}{l}\text { Se coartan las negociaciones colectivas y las huelgas laborales. } \\
\text { Se impide otorgar tierra a dirigentes sindicales, se disuelven las }\end{array}$ \\
$\begin{array}{l}\text { organizaciones sindicales y se promueve la desintegración de } \\
\text { productores }\end{array}$
\end{tabular}

Fuente: Portilla, 2000. 
$\underline{\text { Análisis }}$

Fomento al mercado de la tierra rural

La tenencia de la tierra fue probablemente el aspecto de mayor interés en los primeros años de la reforma del sector. Para 1973, año en que se detuvieron las expropiaciones producto de la reforma agraria impulsada por Salvador Allende, cerca del 65\% — 730 mil hectáreas-de la tierra irrigada y $50 \%$ —9.2 millones de hectáreas - de la tierra agrícola total estaban en manos del sector público (se sugiere ver Valdés, 1995). El anterior gobierno había favorecido la formación de grandes unidades agrícolas bajo la forma de cooperativas y de granjas de propiedad estatal, desalentando a la propiedad privada en la agricultura.

En 1974 se inició un proceso de distribución y restitución de la tierra, conocido como "regularización de la reforma agraria", estableciéndose granjas familiares individuales con una superficie máxima de ocho hectáreas de tierra irrigada o su equivalente. Esto permitió asignar títulos de propiedad a casi 110 mil pequeños productores y a 70 mil indígenas, pero también se restituyó cerca del 30\% de la tierra expropiada a sus antiguos propietarios (Portilla, 2000: 11). Paralelamente, el gobierno alentó la formación de un mercado libre de la tierra al autorizar la venta y renta de parcelas y derechos asignados sin restricción alguna, posibilitando el acceso a ella a la inversión privada no ligada tradicionalmente a la agricultura (véase Dubreucq, 1994). En 1978 se decretó una nueva ley que impedía las expropiaciones de la tierra por parte del gobierno.

Los intentos por alcanzar una mejor distribución de la tierra, es decir, un cambio estructural en la propiedad de la misma, constituyeron una de las bases fundamentales para el desarrollo de una agricultura de tipo empresarial más acorde con los requerimientos del mercado, basada en la productividad y la rentabilidad más que en el uso extensivo del suelo facilitado por el tamaño de los predios. Aunque si bien las restricciones crediticias y la falta de asistencia técnica seguían siendo los principales obstáculos en este proceso, estos cambios en la distribución de la tierra se tradujeron en un aumento en el número de minifundios como resultado de las subdivisiones de las parcelas asignadas y de parcelaciones en comunidades indígenas, y en un aumento de las explotaciones familiares. Pero por otro lado se multiplicaron las unidades de tamaño medio derivadas de la restitución de predios y se abrió el camino para la formación de grandes empresas agroindustriales (véase Canales Cerón, 1996).

\section{Cuadro 3}

Chile: cambios en la tenencia de la tierra, 1965-1979

(\%)

\begin{tabular}{lrr}
\hline Tamaño en has. & 1965 & 1979 \\
\hline Menores de 5 & 9.6 & 14.6 \\
De 5 a 20 & 12.7 & 40.3 \\
De 20 a 80 & 22.5 & 26.9 \\
Mayores de 80 & 55.2 & 18.2 \\
Total & 100.0 & 100.0 \\
\hline
\end{tabular}

Fuente: Portilla, 2000.

\section{Liberalización de los mercados} agropecuarios

En 1970 había una excesiva intervención del gobierno en la agricultura por conducto de dependencias estatales vinculadas directamente con las actividades agrícolas. Para 1974, con los cambios radicales emprendidos en el sector público, se eliminaron todos los monopolios estatales en la comercialización interna y externa de insumos y productos agropecuarios; algunos de ellos, como la Empresa de Comercio Agrícola (ECA), desaparecieron, mientras 
que otros como la Industria Azucarera Nacional (IANSA) fueron privatizados. Se esperaba que la oferta y la demanda permitieran una eficiente asignación de los recursos mediante la liberalización de precios de los insumos y productos agrícolas. La intención era que a mediano plazo se diera una alineación de los precios internos con los precios internacionales, supuestamente no subsidiados.

No obstante, en el caso de algunos rubros que se consideraban sensibles o estratégicos, se mantuvo cierta protección. Por razones estratégicas y de seguridad, aunadas a presiones de sectores empresariales agrícolas vinculados al régimen, se determinó un trato especial para algunos alimentos considerados como básicos. Se argumentó que era necesario asegurar una proporción importante del abastecimiento interno de alimentos básicos, aunque ello implicaba una contradicción respecto de la política económica neoliberal adoptada.

De esta forma, entre 1974 y 1978 ECA mantuvo el control de la comercialización interna y externa de productos como el trigo, maíz, arroz, papa, carne y leche, entre otros. Esta intervención del gobierno tendería a disminuir gradualmente hasta llegar a su desaparición en 1981. Únicamente el trigo y las oleaginosas quedaron bajo un sistema de precios de referencia, mientras que la remolacha quedó sujeta a un precio fijado en dólares y manejado bajo contrato. Este mecanismo de control sobre los precios agrícolas, conocido como bandas de precios, mediante el cual se fijaba un precio mínimo y un máximo para los distintos productos agrícolas se suprimió en 1979 por petición de los propios productores, debido a que los precios internacionales habían rebasado a los precios máximos internos. Con ello se eliminaba la más importante medida de intervención estatal directa dentro de la política agrícola.
Respecto al mercado de insumos, se siguió la misma orientación en términos de eliminar las transferencias al sector agropecuario. Esto implicó una drástica disminución de los subsidios a los insumos derivados de líneas de crédito preferenciales con tasas de interés menores que las del mercado. Adicionalmente se suprimieron las exenciones y reducciones de impuestos en las importaciones de insumos como fertilizantes, semillas y pesticidas, lo que provocó importantes alzas en los costos de producción.

Del mismo modo, en congruencia con la liberalización del comercio se privatizaron las principales empresas estatales que operaban en la regulación de los diversos mercados agrícolas, como la Empresa $\mathrm{Na-}$ cional de Frigoríficos (Enafri), la Sociedad de Comercialización Agropecuaria (Socoagro), la Empresa Nacional de Semilla (ENDS), entre otras. Este retiro del Estado de las actividades agropecuarias se dio como parte de un programa más amplio de privatizaciones. Cabe subrayar que para 1980 quedaban bajo control del gobierno sólo 43 de las 500 empresas que se habían estatizado o intervenido anteriormente (Portilla, 2000: 14).

\section{Financiamiento rural}

A principios de los años setenta la agricultura contribuía con $10 \%$ del producto interno bruto (PIB), pero en cambio absorbía alrededor de $30 \%$ del crédito total de las instituciones financieras. La banca estatal otorgaba créditos a tasas de interés por debajo de las tasas de mercado y fungía como proveedor de fertilizantes y otros insumos, es decir, podía vender insumos agrícolas a precios menores que los precios de mercado. Además, se eximió del pago de impuestos a las importaciones y se otorgaron redescuentos en los créditos

MÉXICO YLACUENCADELPACÍFICO vol. 9, núm. 27 / enero-diciembre de 2006 
contraídos.

A partir de 1974 estas concesiones quedaron suprimidas al desaparecer el redescuento en las deudas y las líneas de crédito preferenciales. Con ello, el gobierno fue reduciendo la influencia de los grupos de presión, quienes se habían visto favorecidos con préstamos blandos siempre que enfrentaban condiciones adversas. No obstante, la banca estatal mantuvo algunas líneas de crédito para la agricultura, pero a tasas de interés comerciales y con criterios más selectivos. Paralelamente, entre 1974 y 1981 se modificó radicalmente la importancia del capital privado como fuente de financiamiento para la agricultura, ya que éste pasó de 9 a $76 \%$ del crédito total otorgado al sector. Esto significa que en un lapso de tiempo relativamente corto los productores agropecuarios, además de tierra, contaron con financiamiento suficiente para emprender todo un proceso de transformación del agro chileno.

Sin embargo, este ambiente de abundantes flujos financieros internos y externos de fácil obtención provocó un acelerado proceso de endeudamiento que comprometía fuertemente el patrimonio de los productores, particularmente de los medianos y pequeños, quienes se volvieron cada vez más vulnerables ante cualquier fluctuación de los mercados agropecuarios nacional e internacional o ante cualquier cambio en las expectativas económicas del país. En este periodo el monto de los créditos pasó de 14 a 91\% del PIB agrícola (con base en Cox, 1983).

Esta situación, que se manifestó también en otros sectores económicos, desató una crisis generalizada con el colapso del sistema financiero privado del país, obligando al gobierno a intervenir los principales bancos con un costo equivalente a 20 veces el PIB agropecuario chileno del año 1983. Con ello, el supuesto de que el endeudamiento privado era más eficiente que el público quedó en entredicho. El Banco Central se vio en la necesidad de apoyar tanto a los mayores deudores como a los grandes bancos privados, de tal forma que quienes tenían obligaciones en dólares fueron beneficiados con un tipo de cambio subsidiado y con el establecimiento de un esquema para convertir deudas en dólares a moneda nacional (véase French-Davies y Rosales, 1998).

Para principios de los ochenta era innegable que la apertura comercial y la falta de control en el rápido crecimiento de los flujos de financiamiento habían conducido a un insostenible déficit en la cuenta corriente cercano a $17 \%$ del PIB, en tanto que la deuda externa se había elevado hasta alcanzar $46 \%$ del PIB (French-Davies y Rosales, 1998).

\section{Política de riego}

A partir de 1974 los apoyos estatales para la infraestructura de riego experimentaron una fuerte reducción, al considerarse que la construcción de obras de riego sería responsabilidad del sector privado. Como consecuencia, ninguna obra de riego nueva mediana o mayor sería construida por el Estado, sólo se financiarían obras mayores que representaran realmente un beneficio social. Con ello, la superficie de riego se mantuvo estancada entre 1974 y 1989. Con la introducción del derecho de aprovechamiento de aguas se facilitó la apropiación de tierras, particularmente en zonas de escasos recursos hídricos y alta disponibilidad de suelos con un clima privilegiado para la fruticultura.

\section{Innovación y desarrollo tecnológicos}

La generación de tecnología agropecuaria estaba básicamente en manos del Instituto 
de Investigaciones Agropecuarias (INIA), mismo que había sido fundado en 1964. Para mediados de los setenta, este último manejaba $90 \%$ de los recursos destinados por el Estado a la investigación y extensión agropecuaria. Al igual que en otros países, se buscaba aumentar la oferta de alimentos básicos, considerada como insuficiente, mediante la generación y utilización de paquetes tecnológicos de alto rendimiento que permitieran incrementar la productividad. Hasta 1973 el INIA suministró a los productores conocimientos e insumos prácticamente sin costo alguno. Además, se creó una red de centros experimentales que desempeñaron una función fundamental en el desarrollo tecnológico del campo.

Con el arribo del régimen militar, se determinó que los productores deberían buscar el acceso a las tecnologías para modernizar sus sistemas de producción, por lo que ahora sólo se financiarían aquellas actividades con bajo nivel de productividad y competitividad. Fue así como el INIA suspendió sus apoyos a las actividades pecuarias y redujo la investigación frutícola sólo a aquellos ámbitos que el sector privado no podía o no quería abordar. No obstante, dicho organismo continuó con los trabajos de mejoramiento genético, básicamente de cereales, leguminosas, papas y en menor grado de hortalizas y forrajes, así como con los programas de investigación vinculados al manejo agronómico de los cultivos, control de plagas y fertilidad de los suelos, cuyos resultados y difusión serían de gran importancia para el mejoramiento de la producción agrícola.

A partir de 1979 los recursos del INIA disminuyeron drásticamente y se vio en la necesidad de obtener recursos propios mediante la venta de sus servicios. En materia de transferencia de tecnología, se suprimieron los servicios del Servicio Agrícola y Ganadero (SAG) y de la Corporación de la Reforma Agraria (CORA), manteniéndose solamente los programas del Instituto de Desarrollo Agropecuario (INDAP) bajo la modalidad de asistencia técnica privada a través de un subsidio a la demanda que iría descendiendo progresivamente (Portilla, 2000: 16).

\section{Fomento a las actividades forestales}

El nuevo gobierno decidió otorgar un decidido impulso al desarrollo del subsector forestal mediante grandes subsidios a las plantaciones forestales. Esto se traduciría en un acelerado crecimiento de la superficie forestal al pasar de 400 mil a un millón de hectáreas entre 1974 y 1981, lo cual sentó las bases para el posterior auge de las exportaciones forestales. A finales de los noventa, $80 \%$ de las plantaciones forestales se encontraban en predios mayores de 200 hectáreas y $60 \%$ en predios de más de 1,000 hectáreas, alcanzándose una fuerte concentración de esta actividad en pocas pero grandes empresas verticalmente integradas. Paulatinamente las actividades forestales se fueron extendiendo a suelos ganaderos y agrícolas, cuyos ex propietarios se convirtieron de pequeños campesinos a trabajadores asalariados.

Fue así como la intervención del gobierno en las actividades agropecuarias, hasta principios de los ochenta, se redujo básicamente a investigación y transferencia de tecnología, inspección sanitaria, financiamiento a los pequeños productores, una mínima intervención en la comercialización de algunos productos básicos y a promover las plantaciones forestales. Este alineamiento de la política agrícola al marco de la política macroeconómica se vería modificado como consecuencia de la creciente diferenciación en el dinamismo de las regiones y de los subsectores agrícolas tradicional y moderno, y ante

MÉXICO YLACUENCADEL PACÍFICO vol. 9, núm. 27 / enero - diciembre de 2006 
la necesidad de programas sociales que permitieran contrarrestar las presiones derivadas de la recesión económica que comenzaba a gestarse.

\section{Segunda fase de las reformas, 1984-1989: reajustes en la apertura}

El paulatino deterioro en las condiciones económicas internas como consecuencia de la crítica situación del sistema financiero y de una revalorización del tipo de cambio, entre otros factores, se vio agravado con la crisis de la deuda de 1982 que se inició en México y se propagó a la mayor parte de los países de la región. Esta situación condujo a un viraje obligado en la política económica en general y del sector agropecuario en particular, que se tradujo en la aplicación de medidas e instrumentos que contradecían en cierta forma a la lógica neoliberal precedente. La intervención de los mercados agropecuarios y el restablecimiento de una serie de subsidios y mecanismos de fomento a la agricultura por parte del Estado, dan cuenta de ello. De igual forma, el proceso de privatización de grandes empresas estatales llevado a cabo con facilidades especiales y algunas irregularidades en las adjudicaciones, escapaban a un transparente funcionamiento del libre mercado y de la doctrina vigente (cuadro 4).

A pesar de lo anterior, las medidas de política, aunque con altibajos, vinieron a consolidar el modelo exportador chileno con un tipo de cambio al alza y manteniendo la apertura externa. En efecto, en materia de aranceles por ejemplo, después de la decisión de elevarlos de 10 a $35 \%$ para 1984, éstos descendieron a $15 \%$ en 1988. Por su parte, el tipo de cambio real subió un $25 \%$ en $1985,13 \%$ en 1986 , hasta alcanzar en 1988 un nivel superior en 70\% al registrado a principios de los ochenta (French-Davies y Rosales, 1998). En cuanto al sector agropecuario, a continuación se describen los cambios más importantes en la política agrícola respecto al periodo precedente.

Cuadro 4

Principales cambios en la política agrícola entre 1984 y 1989

\begin{tabular}{ll}
\hline Medidas de política más importantes & Instrumentos \\
\hline Estabilización de precios & $\begin{array}{l}\text { Establecimiento de bandas de precios en trigo, aceite y azúcar } \\
\text { para atenuar cambios en los precios internacionales. Intervención } \\
\text { en la comercialización de trigo mediante la empresa Cotrisa. } \\
\text { Medidas antidumping en importaciones de cereales, frutas, } \\
\text { hortalizas y lácteos. Bolsa de productos agropecuarios y centros } \\
\text { de acopio para pequeños productores. }\end{array}$ \\
Fomento a las exportaciones & $\begin{array}{l}\text { Reintegro de derechos de importación de materias primas e } \\
\text { insumos para exportadores chilenos. }\end{array}$ \\
Política de riego & $\begin{array}{l}\text { Subsidios a obras de riego para incorporar nuevas superficies } \\
\text { de riego. }\end{array}$ \\
Política tecnológica & $\begin{array}{l}\text { Disminución de los apoyos estatales a investigación y desarrollo. } \\
\text { Creación de fondos concurrentes para fomento del financiamien- } \\
\text { to privado a investigación. }\end{array}$
\end{tabular}

Fuente: elaborado con base en Portilla, 2000. 


\section{Estabilización de los precios}

Como parte de los esfuerzos del gobierno para reactivar la agricultura, se aplicó una política tendente a atenuar el efecto de las fluctuaciones de los mercados agrícolas internacionales sobre los precios internos de algunos productos considerados como sensibles. Se buscaba generar un panorama de mayor confianza y estabilidad en la producción agrícola, de modo que los productores agrícolas tuvieran asegurados, antes de la siembra, los precios mínimos que regirían al momento de las cosechas.

Los instrumentos utilizados por el gobierno serían el mecanismo de las bandas de precios para asegurar la oferta de alimentos y precios estables en productos como trigo, azúcar y aceite. Adicionalmente, se intervino nuevamente la comercialización de trigo como medida de apoyo a los productores, especialmente durante la caída de los precios internacionales de mediados de los ochenta, y se establecieron medidas antidumping para las importaciones de arroz, maíz, frutas, hortalizas, leche en polvo y descremada. El efecto de todas estas medidas fue que los productos agropecuarios de mayor importancia recibieron durante algunos años un nivel de protección nominal superior al arancel general uniforme (véase Errázuriz y Muchnik, 1996).

\section{Fomento a las exportaciones}

A partir de 1985, como medida para estimular las exportaciones se creó un mecanismo mediante el cual se reintegraban a los exportadores chilenos los derechos de importación pagados por materias primas e insumos utilizados en aquellas exportaciones menores de 2.4 millones de dólares. Inicialmente, la devolución consideraba el $10 \%$ del valor, excluyendo comisiones y cualquier otro gasto de exportación, y suponiendo un componente de importación del $50 \%$.

En 1987 se incluyó un reintegro de $10 \%$ para los rubros no tradicionales que durante un año se hubieran exportado por un monto igual o inferior a 10 millones de dólares, de 5\% para las exportaciones mayores de 10 millones y de $3 \%$ para las que se ubicaban entre más de 15 y menores de 18 millones de dólares. De manera adicional, en 1988 se agregó un reintegro de 10 a 15\% por los insumos nacionales exportables incorporados a los productos exportados. El objetivo era corregir la discriminación sobre la industria nacional y sobre el valor agregado de las exportaciones.

Este subsidio, que se mantuvo hasta 1995, se perdía si en un año se rebasaban los montos señalados o si en los últimos tres años calendario, los montos exportados no mostraban aumentos de al menos 1.5 veces el crecimiento promedio del PIB. Entre 1991 y 1995 el monto de este apoyo representó $2 \%$ de las exportaciones agropecuarias, lo cual significa que si bien favoreció el impulso inicial de las exportaciones no tradicionales, su efecto sobre las mismas no fue de gran importancia (Errázuriz y Muchnik, 1996). Sin embargo, como parte del Acuerdo sobre la Agricultura alcanzado dentro de la Ronda Uruguay del GATT (hoy OMC), Chile se comprometió a eliminar este programa para el año 2003.

\section{Política de riego}

El gobierno también creó una ley de fomento al riego que incluía un programa de subsidios a las obras hidroagrícolas tendentes a aumentar la superficie de riego, así como a mejorar las existentes. Entre 1983 y 1989 se asignaron 34 millones de dólares en beneficio de 900 familias de agricultores y una superficie de riego de alrededor de 300 
mil hectáreas. La relación de poco más de 300 hectáreas por agricultor mostraba el alto grado de concentración de los beneficios, mientras que sólo 4\% del total de los recursos se destinó para el único concurso campesino llevado a cabo en dicho periodo (véase Muchnik, 1997).

No obstante, la aplicación de esta medida de la política agrícola permitió aumentar la inversión pública con participación del sector privado en un aspecto fundamental para mejorar la productividad agrícola. Posteriormente, en 1992 se puso en marcha un programa de rehabilitación y construcción de obras de riego medianas y menores para facilitar el acceso de los pequeños productores, con un monto superior a los 100 millones de dólares. Con este programa se buscó impulsar más proyectos de desarrollo agrícola, al incorporarse cerca de 55 mil hectáreas de riego y mejorarse los sistemas de riego en otras 105 mil hectáreas.

\section{Impulso a la tecnología}

La participación del gasto público en investigación y desarrollo, que ascendía a $80 \%$ del total en este campo, fue disminuyendo a partir de 1986 hasta representar 60\% a finales de los noventa. Sin embargo, esta reducción de los apoyos del Estado, canalizada principalmente a universidades e institutos tecnológicos, se vio compensada con la creación de fondos concurrentes mediante los cuales se buscó una mayor participación de la inversión privada en el financiamiento a la investigación.

Fue así como el gasto en investigación y desarrollo en el sector agropecuario chileno alcanzó un punto porcentual del PIB agrícola, con modalidades de financiamiento acordes con la tendencia internacional en este sentido. Con ello, se redujeron significativamente los apoyos directos del Estado al INIA y se fortalecieron los fondos concurrentes, los cuales pasaron a representar $20 \%$ del total sectorial. Pero, a diferencia de los países desarrollados en los cuales los aportes por este medio son compartidos por el Estado y el sector privado en partes iguales, en Chile el gobierno era el que aportaba los fondos en forma mayoritaria (Muchnik, 1997).

Además, esta forma de financiar la investigación y desarrollo privilegió a las actividades de investigación orientadas a generar innovaciones tecnológicas en el corto plazo, en perjuicio de aquéllas de carácter más estratégico, las cuales por el tiempo requerido para su maduración y aplicación no estaban en las prioridades de los fondos ni eran de interés para el capital privado. Esto obligó nuevamente a los organismos públicos a financiar investigaciones de mediano y largo plazos, como las de fitomejoramiento, por medio de acuerdos con la iniciativa privada o a participar directamente en los mercados de insumos, particularmente en la comercialización de semillas mejoradas.

\section{Tercera fase de las reformas, 1990-2004: inserción en el mercado internacional}

Con el arribo del primer gobierno democrático en Chile, aunque manteniendo el mismo modelo de apertura al exterior, la política agrícola dio un giro significativo hacia la ruralidad, con una visión más incluyente y en reconocimiento a la heterogeneidad social y productiva del campo chileno. Así como la internacionalización de la economía, y de la agricultura en particular, empujaba al gobierno a buscar acuerdos comerciales, tecnológicos y financieros que generaran las condiciones óptimas para fortalecer la competitividad y la capacidad de gestión de la empresa agrí- 
cola, se consideró que el Estado también debía apoyar a los agricultores más débiles, proporcionándoles los instrumentos necesarios para su inserción en los mercados nacional e internacional, así como el acceso a la tecnología y al financiamiento.

Adicionalmente, se planteó que para enfrentar la pobreza y marginación rural se debían combinar las políticas orientadas a la integración económica y productiva con políticas sociales. Se puso énfasis en la necesidad de un desarrollo rural sustentable, comprometiéndose a proteger el ambiente, así como a la restauración de zonas degradadas. Este enfoque más integral de la agricultura chilena implicó un leve aumento de uno a dos puntos porcentuales en el gasto total del gobierno destinado a la agricultura, pero con beneficios mucho más amplios que en las etapas anteriores.

Las acciones implementadas más importantes en esta fase se describen a continuación.

\section{Integración al mercado internacional}

El gobierno chileno profundizó la apertura de la economía y de la agricultura chilena mediante el establecimiento de acuerdos de liberalización comercial de carácter multilateral y bilateral, con la finalidad de reducir los aranceles y, con ello, disminuir las distorsiones en los precios internacionales de los productos agrícolas, pero sobre todo para lograr un mayor intercambio comercial y una mejor integración de la agricultura chilena al mercado internacional.
Cabe subrayar que la presencia de Chile en el contexto internacional no es reciente, este país ha venido participando en diversos foros internacionales multilaterales desde hace tiempo, promoviendo y apoyando iniciativas relativas tanto al comercio internacional como a la integración regional. En 1948, junto con otros 23 países, participó en la formación del Acuerdo General de Aranceles Aduaneros (GATT), la cual se transformó recientemente en la Organización Mundial del Comercio (OMC), con el propósito de estimular el desarrollo económico de las naciones a través del comercio, con base en la reducción de los aranceles y de las restricciones no arancelarias en general.

La estrategia de la OMC, que agrupa a 144 países y regula alrededor de $90 \%$ del comercio mundial de productos agrícolas, es la realización de rondas de negociaciones comerciales multilaterales para la reducción de los subsidios y de las tarifas arancelarias. A la fecha se han celebrado nueve rondas, la última de ellas la Ronda de Doha iniciada en el año 2000 en Qatar y aún en proceso de negociación. Chile ha participado activamente en todas las rondas, lo que se ha traducido en mejores condiciones de acceso para una alta proporción de sus productos agrícolas de exportación.

Paralelamente, Chile se adhirió al Grupo CAIRNS, el cual integra a 17 países que se caracterizan por su condición de exportadores netos de productos agropecuarios sin subsidios y de ser promotores del libre comercio. ${ }^{1}$ Respecto al Mecanismo de Cooperación Asia Pacífico (APEC), fundado en 1989, del que Chile también forma parte y

MÉXICO YLACUENCADEL PACÍFICO vol. 9, núm. 27 / enero-diciembre de 2006 
Análisis

\author{
Cuadro 5
}

Principales cambios en la política agrícola entre 1990 y 2004

\begin{tabular}{ll}
\hline Medidas de política más importantes & Instrumentos \\
\hline Integración al mercado internacional & Acuerdos multilaterales y bilaterales de liberalización comercial. \\
Estabilización de precios & $\begin{array}{l}\text { Sostenimiento de bandas de precios en trigo, aceite y azúcar. } \\
\text { Ampliación de cobertura de Cotrisa. Sistemas de información de } \\
\text { precios y de mercados. }\end{array}$ \\
Fomento a la competitividad & $\begin{array}{l}\text { Apoyo a rubros considerados como sensibles y aquéllos de creciente } \\
\text { expansión en el exterior. Apoyo a obras de riego y a programas de } \\
\text { recuperación de suelos. }\end{array}$ \\
Apoyo a la pequeña agricultura & $\begin{array}{l}\text { Apoyo a incorporación de la pequeña agricultura a los circuitos } \\
\text { comerciales. Asistencia técnica a empresas privadas. }\end{array}$ \\
\hline
\end{tabular}

Fuente: elaborado con base en Portilla, 2000; ODEPA, 2005b, 2006; Presidencia de la República, 2003.

que procura la liberalización del comercio y las inversiones entre sus miembros, el país andino se comprometió a reducir sus aranceles a cero por ciento para el año 2010 , en condiciones recíprocas para la mayor parte de los productos (cuadro 5).

En el ámbito regional el gobierno chileno también ha tenido una activa participación en la promoción de un área de libre comercio latinoamericana, para lo cual suscribió, junto con otros países de la región, el Tratado de Montevideo de 1960 mediante el cual se creó la Asociación Latinoamericana de Libre Comercio (ALALC). No obstante, los múltiples problemas económicos que enfrentaban los países en esa época y la diversidad de enfoques y políticas internas para encauzar el desarrollo impidieron avanzar en esta iniciativa regional (ODEPA, 2006).

Debido a los pobres resultados del ALALC desde su creación, la comunidad latinoamericana buscó un mecanismo diferente y más eficiente de avanzar hacia la liberalización del comercio y la integración regional. Fue así como Chile y otros 10 países de la región crearon la Asociación
Latinoamericana de Integración (ALADI) mediante el Tratado de Montevideo en 1980. Como parte de este tratado Chile firmó lo que se denominó como Acuerdos de Alcance Parcial (AAP) con Argentina, Bolivia, Brasil, Colombia, Ecuador, México, Paraguay, Perú, Venezuela y Uruguay. Bajo el esquema de la ALADI los países continuaron negociando y concediéndose preferencias, modificando y aumentando las ventajas recíprocas, lo que en última instancia ha constituido la base de los Acuerdos de Complementación Económica (ACE) firmados más recientemente con la mayoría de los países de América Latina, que vinieron a sustituir a los AAP.

En forma simultánea Chile ha venido firmando una serie de tratados bilaterales de libre comercio con diversos países, entre ellos México, Canadá, Centroamérica, Corea del Sur, Estados Unidos, la Asociación Europea de Libre Comercio (EFTA, por sus siglas en inglés), Nueva Zelanda, Singapur y Brunei Darussalam. Actualmente están a punto de concretarse otros tratados comerciales con Japón y China.

Con estos acuerdos comerciales mul- 
tilaterales y bilaterales Chile ha buscado consolidar su apertura económica y la ampliación del mercado externo para su producción nacional, particularmente para las exportaciones agropecuarias. Concretamente, lo que se pretende es avanzar en los plazos de desgravación para los principales productos de exportación del sector, como son las frutas, hortalizas, lácteos, carnes de aves y cerdo, semillas y vinos. Pero, por otro lado, se ha tratado de excluir de los procesos de desgravación o negociar plazos más largos para aquellos productos más sensibles como trigo, azúcar, arroz y carne de bovino ((ODEPA, 2006).

En términos generales, la postura chilena en las negociaciones comerciales se podría resumir en los siguientes puntos:

- Apoyar la liberalización del comercio exterior en los foros multilaterales (OMC, APEC, CAIRNS, etcétera).

- Superar algunas normativas de la OMC donde sea posible y recomendable.

- Incorporar al sector agropecuario en la negociación de cada acuerdo bilateral, reconociendo sus sensibilidades y particularidades.

- Proceder de manera congruente en las negociaciones agrícolas con diferentes países o grupos de países, reconociendo la especificidad de los mismos.

- Avanzar simultáneamente en las negociaciones arancelarias y no arancelarias.

\section{Estabilización de precios}

En relación con la estabilización de precios, solamente se mantienen las bandas de precios para el trigo, la harina de trigo y el azúcar, con la finalidad de atenuar las fluctuaciones internacionales de los precios de estos productos y, con ello, mantener la estabilidad del mercado nacional. ${ }^{2}$ Adicionalmente, se amplió la cobertura de compra de la empresa estatal Comercializadora de Trigo (Cotrisa) hacia zonas en donde predomina la pequeña agricultura cerealera, con el apoyo de organizaciones de productores.

Por otra parte, se fortaleció la transparencia de los mercados internos mediante diversas iniciativas enfocadas hacia una mayor difusión de información sobre los precios agrícolas, los cuales son monitoreados en forma permanente por la Oficina de Estudios y Políticas Agrícolas (ODEPA) del Ministerio de Agricultura de Chile. A su vez, el desempeño de los distintos subsectores es evaluado por conducto de comisiones especializadas, las cuales convocan a los distintos agentes involucrados para evaluar la problemática y aportar soluciones.

\section{Fomento de la competitividad}

Desde inicios de los años noventa la política agrícola chilena se ha enfocado en fortalecer la competitividad de la agricultura en una doble dirección. Por un lado, apoyando aquellos rubros considerados más vulnerables frente a la competencia externa, los cuales son justamente aquellos que han recibido un tratamiento especial en los plazos de desgravación arancelaria, como son cereales, carne y leche. Por otro, fortaleciendo los rubros cuya inserción en el mercado internacional ha mostrado una creciente expansión o que presentan un fuerte potencial exportador, como son las frutas, hortalizas, semillas, vinos y otros productos agroindustriales.

Otras medidas complementarias para fomentar la competitividad han consistido en retomar las grandes y medianas obras de riego, facilitando su acceso a la pequeña agricultura. Asimismo, se han apoyado estudios de validación de riego tecnificado, junto a la introducción de nuevos 
cultivos en las áreas de nuevo riego. ${ }^{3}$ Por último, se ha implementado un programa permanente de recuperación de suelos, especialmente en las regiones ganaderas, afectados por la acidificación derivada del creciente uso de fertilizantes.

\section{Apoyo a la pequeña agricultura}

Sin duda, constituye uno de los rasgos más distintivos respecto a las políticas agrícolas precedentes debido al propósito explícito de apoyar a la pequeña agricultura, así como de mejorar el bienestar social de la población rural que en general paulatinamente se ha visto marginada del desarrollo e, incluso, deteriorado su nivel de vida.

En Chile la pequeña agricultura representa un conjunto heterogéneo de alrededor de 280,000 pequeños productores - de un total nacional de 330,000 productores-que poseen cerca de $9.2 \mathrm{mi}$ llones de hectáreas y aportan una cuarta parte del PIB agropecuario. De este grupo, cerca de $37 \%$ — casi 103,000 - son campesinos o productores de subsistencia, pero sólo poseen $3 \%$ del total de la superficie agrícola sembrada (con base en cifras de ODEPA, 2005a). Cabe señalar que gran parte de los pequeños agricultores, aun cuando enfrentan una constante presión por asegurar su viabilidad, han podido introducir innovaciones técnicas y de gestión y acceder al financiamiento para adaptarse a las nuevas condiciones de los mercados nacional e internacional. Pero, por otro lado, muchas unidades campesinas marginadas de este proceso han experimentado un fuerte deterioro de sus escasos recursos, se encuentran bajo la línea de pobreza y sus ingresos provienen en su mayor parte de actividades no agrícolas.

Ante tales circunstancias, la política agrícola se ha orientado a apoyar una mayor incorporación de la pequeña agricultu- ra a los circuitos comerciales; sin embargo, esto no la ha protegido de sufrir los efectos más drásticos de las políticas de ajuste y de cambio estructural. En términos generales, además de la asistencia técnica otorgada por el gobierno, las acciones de apoyo se han centrado en el fomento a las organizaciones de productores para una mejor inserción de los pequeños productores en el mercado. De ahí que se ha estado apoyando la formación de sociedades comerciales, fortaleciendo la capacidad de gestión tanto en sus procesos productivos como administrativos.

En relación con los sectores más desfavorecidos, se ha pretendido que las medidas de política trasciendan el ámbito sectorial para tener un carácter multisectorial. Para ello se han impulsado una serie de medidas que consideran metas en materia de educación, salud, vivienda, electrificación, agua potable, vialidad y comunicaciones. En 1997 se aprobó el Plan de Desarrollo de Zonas de Pobreza Rural a partir de políticas aprobadas por un comité integrado por los responsables de la política social.

Sin embargo, parece que el problema de la dispersión a que se han sometido los programas e instrumentos públicos ha provocado que las acciones tengan realmente poco impacto. Aun así, se ha insistido en tales políticas para mejorar el acceso de la población rural a los servicios básicos, reforzándose aquéllas orientadas a mejorar los niveles de ingreso, particularmente de los más pobres. Pese a los avances, las carencias en el medio rural son aún críticas $\mathrm{y}$ los indicadores de pobreza e indigencia se mantienen altos.

Lo que se debe resalta aquí es que la política agrícola chilena de los años noventa en adelante puso un énfasis en la revalorización del medio rural en reconocimiento a la heterogeneidad del 
campo chileno. Ello implicó la aplicación de medidas para apoyar la inserción de los pequeños productores agrícolas en los mercados, así como instrumentos de fomento para las asociaciones y organizaciones de productores. Entre estas medidas destacan los programas regionales para el impulso a la infraestructura de riego y el establecimiento de praderas, forestación y manejo del bosque; así como aquéllos de fomento a la comercialización y exportación de productos agropecuarios (Kay, 1996).

\section{Evolución del sector agropecuario chileno}

\section{Comportamiento del PIB agropecuario}

La evolución del PIB agropecuario muestra también tres etapas distintas a partir de la aplicación de las reformas. En la primera etapa, de 1974 a 1983, hubo una recuperación en el crecimiento de la producción agrícola, aunque si bien la tasa fue de apenas $1.3 \%$ promedio anual, posteriormente hubo un retroceso en los años de la crisis al caer la producción - $1.7 \%$ en 1982 y -3.4\% en 1983. En esa década el sector agropecuario experimentó las tasas de crecimiento más bajas, incluso menores que las registradas durante los años sesenta (cuadro 6).

Después de la primera década de las reformas los resultados obtenidos estaban lejos de lo esperado. Se había previsto que los rubros de consumo interno, que en el periodo precedente habían tenido la más baja protección efectiva, experimentarían un mayor dinamismo al generarse las condiciones necesarias para una mayor rentabilidad mediante un doble mecanismo. Por un lado, la reducción arancelaria permitiría la importación de insumos y maquinaria a menores costos y, por otro, la liberación de los precios internos permitiría generar mayores ingresos para los productores.
De igual forma, se esperaba que la política de un tipo de cambio real al alza apoyara el crecimiento de los rubros de exportación. Sin embargo, la política cambiaria tuvo un comportamiento irregular y provocó una subvaluación del tipo de cambio. En efecto, el proceso de liberalización y apertura de los mercados agropecuarios se dio en un marco de desgravación arancelaria, pero con un tipo de cambio que generó una apreciación del peso, lo cual facilitó las importaciones en un contexto de baja en los precios internacionales de algunos de los rubros más importantes, ello aunado a los altos subsidios en los países de origen.

\section{Cuadro 6}

Chile: evolución del PIB agropecuario, 1960-2004

\begin{tabular}{cc}
\hline Periodo & Tasa media anual (\%) \\
\hline $1960-1965$ & 1.8 \\
$1965-1970$ & 3.2 \\
$1970-1973$ & -5.3 \\
$1974-1983$ & 1.3 \\
$1981-1982$ & -1.7 \\
$1982-1983$ & -3.4 \\
$1984-1989$ & 6.4 \\
$1990-1995$ & 5.9 \\
$1996-1999$ & 2.0 \\
$2000-2004$ & 5.8 \\
\hline
\end{tabular}

Fuente: elaborado con base en Muñoz y Ortega, 1994; Portilla, 2000; ODEPA, 2006.

Por otro lado, pese a una disminución efectiva en el costo de los fertilizantes y pesticidas, otros insumos como el petróleo y la energía eléctrica registraron un fuerte aumento, provocando un efecto negativo en la mayoría de los rubros. De acuerdo con algunos estudios, entre 1976 y 1982 la rentabilidad de la mayoría de los cultivos de consumo interno - principalmente trigo, maíz, arroz, frijol, lentejas, garbanzos у papa-, así como de cultivos industriales - como remolacha- había disminuido en- 
$\underline{\text { Análisis }}$

tre 30 y 70\% (Errázuriz y Muchnik, 1996; Canales, 1996).

En la segunda etapa, entre 1984 y 1989, como resultado de las condiciones desfavorables del entorno internacional se reintrodujeron una serie de medidas de apoyo al campo chileno, lo cual se reflejó en una significativa recuperación en crecimiento del PIB sectorial y de las exportaciones agropecuarias, especialmente frutícolas, agroindustriales y forestales. En este periodo el PIB agropecuario creció $6.4 \%$ en promedio por año.

En la tercera etapa, de 1990 a 2004, la producción agropecuaria mostró tres momentos. En primer lugar registró un leve descenso para mediados de los años noventa como consecuencia de la contracción del mercado internacional. Posteriormente, la situación del sector se agravó a finales de esa década por la crisis de Asia, con una drástica caída en el crecimiento del producto agrícola. Finalmente, se observó una importante recuperación del sector, aunque si bien sin alcanzar los niveles de finales de los años ochenta, cuando la agricultura chilena alcanzó sus mayores tasas de crecimiento.

La disminución en la superficie cerealera, la baja en el precio del trigo, la menor rentabilidad de rubros de exportación y la baja en los precios internacionales de algunos productos, aunadas a la crisis de los mercados asiáticos explicarían en gran parte esta situación. Este irregular desempeño del sector agropecuario desde la aplicación de las reformas provocó que la participación relativa de la agricultura en el PIB nacional descendiera de 8 a $4.5 \%$ durante el periodo de 1974 a 2004 debido fundamentalmente al mayor dinamismo de otros sectores económicos, particularmente la minería.

\section{Principales cambios en la estructura} de producción agropecuaria

A principios de los setenta el sector agropecuario chileno experimentó un notable estancamiento en la producción en general debido fundamentalmente al deterioro en las condiciones macroeconómicas y a la incertidumbre que privaba en torno a la tenencia de la tierra; entre los productos que mostraron una fuerte caída en la producción estaban el trigo, arroz, frijol, remolacha, melón, manzana, pera, hortalizas, legumbres, tomates, carne, huevo, leche y miel. Esta situación cambió notablemente desde el inicio de las reformas hasta principios de los ochenta, cuando la producción manifestó una significativa recuperación en la mayoría de los cultivos, excepto en trigo, remolacha y melón; así como en carne de bovino, porcino, ovino, leche y miel. Posteriormente, en los años de la crisis habría nuevamente una caída en la producción, excepto en frutales, cítricos, maíz, arroz, remolacha, tomate, carne de porcino y de aves.

Fue a partir de 1984, y hasta 1990, cuando se presentó una significativa recuperación de la producción agropecuaria, alcanzándose por primera vez la autosuficiencia en trigo y remolacha gracias a las medidas de política adoptadas por el gobierno para fomentar la recuperación de la producción y, con ello, de las exportaciones. En el caso de los cereales, especialmente trigo, arroz y maíz, la recuperación de la producción se vio asociada más a los incrementos en la productividad que a la recuperación de la superficie sembrada. En efecto, los rendimientos de semillas mejoradas de estos tres cultivos, junto con un entorno favorable de precios y costos de los insumos explican tal evolución.

Sin embargo, durante prácticamente toda la década de los noventa el sector nuevamente presentaría una pérdida de 


\section{Gráfica 1}

Chile: evolución de la producción agrícola, 1970-2005

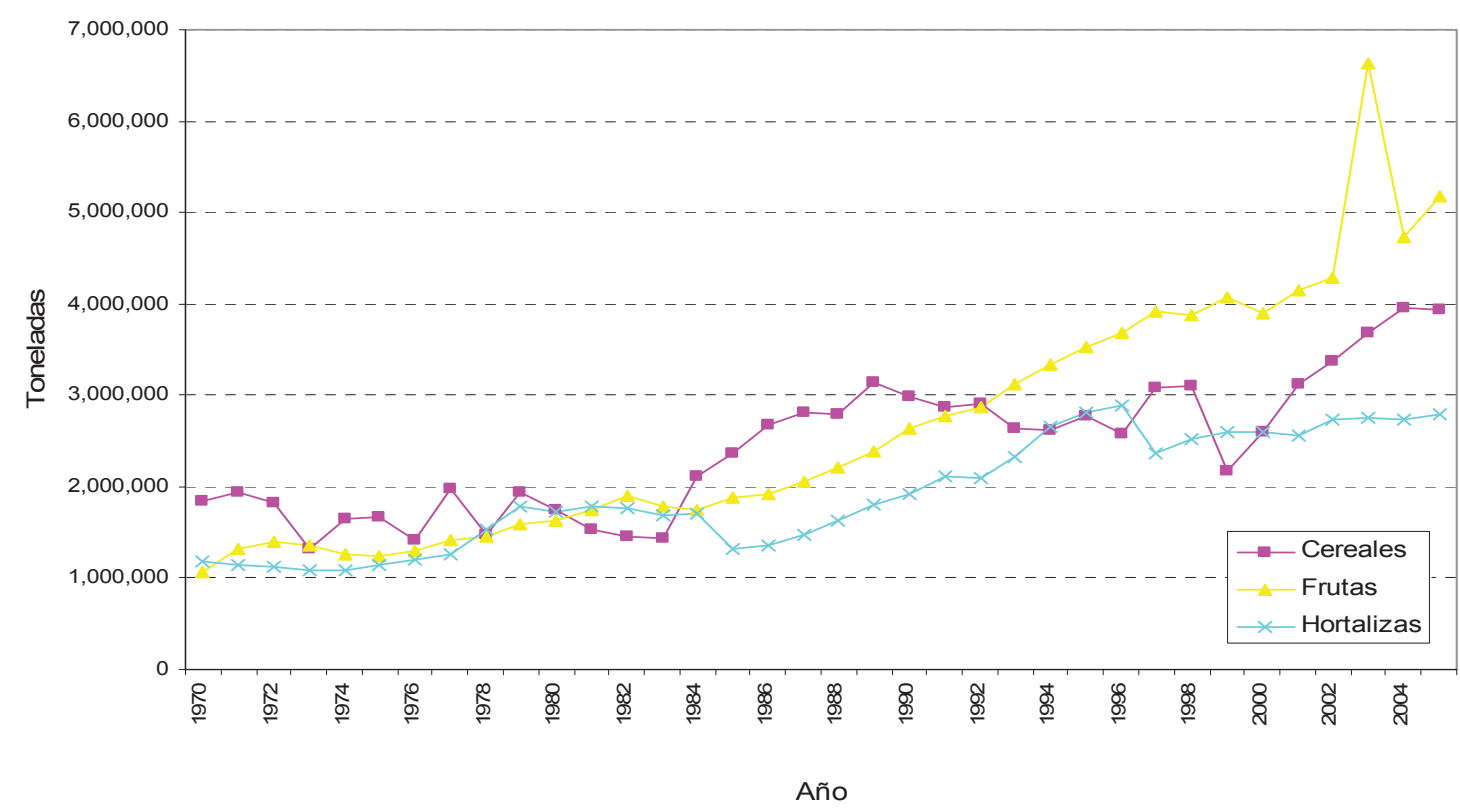

Fuente: elaborada con base en el Banco de Datos de la FAO, Roma, 2007.

dinamismo, excepto en frutas como pera, manzana, melocotón, uva, limón, hortalizas, tomate y avena, así como carne de porcino y de aves. Es decir, mientras los productos básicamente de consumo interno como trigo y maíz presentaron una tendencia descendente en la producción, los productos comerciales o de exportación mantuvieron un crecimiento constante, lo que en cierta forma se ha reflejado en la consolidación del modelo exportador agropecuario chileno.

Posteriormente, a partir del año 2000 la recuperación de los mercados internacionales y el crecimiento del comercio exterior con los países con quienes se concretaron acuerdos comerciales vinieron a darle nuevamente un fuerte impulso a la producción agropecuaria chilena, sobresaliendo la producción de trigo, maíz avena, manzana, uva, remolacha y tomate (gráfica 1).
En los rubros pecuarios se registró un crecimiento espectacular en carne de aves y de porcino, y en menor medida en leche, mismo que se vio asociado a una activa presencia de grandes empresas trasnacionales, las cuales asumieron el control de la agroindustria local con miras al mercado internacional, ello unido al rápido desarrollo del mercado interno. La producción a escala industrial de carne de cerdo explica el hecho de que se haya duplicado su producción en este periodo. En el caso de las aves, su rápido crecimiento se debe al surgimiento de grandes productores altamente integrados, además del fuerte impulso del consumo interno (gráfica 2).

\section{Cambios en el uso del suelo}

El reordenamiento productivo experimentado por el sector agropecuario chileno frente a la apertura y la inserción en los 


\section{Análisis}

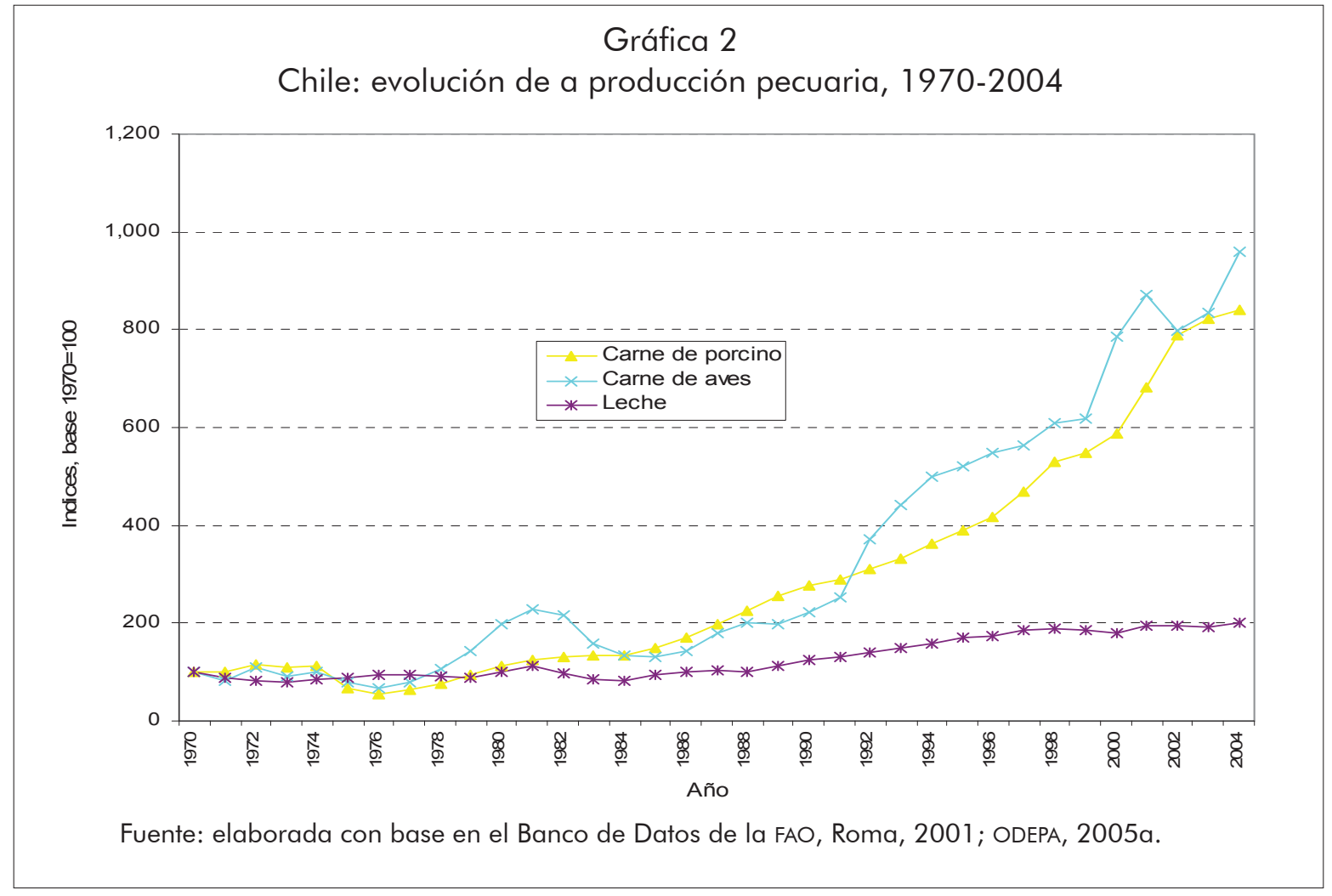

mercados, se reflejó en cambios importantes en el uso del suelo. Entre 1976 y 1997, como se pudo apreciar, hubo un acelerado crecimiento en la superficie sembrada de cultivos frutícolas y forestales, misma que se incrementó en 165 y $75 \%$ respectiva- mente en dicho periodo. Sin embargo, en ambos casos ya existían bases sólidas que se habían desarrollado gracias a las políticas de fomento previas a las reformas, aunque a un ritmo de crecimiento bastante menor.

Cuadro 7

Chile: principales cambios en el uso del suelo, 1965-1997

\begin{tabular}{llllll}
\hline Cultivos & \multicolumn{3}{c}{ Años } & \multicolumn{2}{c}{$\begin{array}{c}\text { Variación } \\
\%\end{array}$} \\
\hline Forestales & \multicolumn{1}{c}{1965} & \multicolumn{1}{c}{1976} & \multicolumn{1}{c}{1997} & \multicolumn{1}{c}{$76-97$ (has.) } & \multicolumn{1}{c}{$76-97(\%)$} \\
Frutas & 85,589 & 627,500 & $1^{\prime} 095,355$ & 467,855 & 74.6 \\
Hortalizas & 87,229 & 89,488 & 236,812 & 147,324 & 164.6 \\
Cereales & 958,164 & 843,895 & 111,871 & 8,976 & 8.7 \\
Leguminosas & 103,184 & 124,831 & 648,111 & $-194,989$ & -23.1 \\
Oleaginosas & 89,538 & 60,308 & 12,018 & $-48,378$ & -62.8 \\
Remolacha & 17,957 & 57,850 & 41,697 & $-16,152$ & -80.1 \\
Forrajes & $11^{\prime} 030,700$ & 609,200 & 608,538 & -662 & -58.9 \\
\hline
\end{tabular}

Fuente: Portilla, 2000. 
En cuanto a los cultivos tradicionales, la superficie sembrada mostró una tendencia descendente. Entre 1976 y 1997 ésta se redujo en alrededor de 300 mil hectáreas, o 376 mil hectáreas si se considera el periodo 1965-1997. Los cereales y leguminosas sufrieron las pérdidas más importantes, mientras que los cultivos hortofrutícolas mostraron una tendencia ascendente en su superficie sembrada (cuadro 7).

En los cultivos industriales, las oleaginosas y la remolacha mostraron una drástica caída en la superficie sembrada, no así en su producción, como se observó antes. Ambos rubros están asociados a las agroindustrias que inicialmente fueron desmanteladas debido al rápido crecimiento de las importaciones. Las medidas de fomento introducidas por el gobierno a mediados de los ochenta permitirían una leve recuperación de la superficie sembrada en el caso de la remolacha.

\section{Comercio exterior}

La apertura de la economía y las reformas en la agricultura chilena han impulsado de manera importante el comercio exterior agropecuario chileno, particularmente durante los últimos años, impulsando a los agentes productivos a adaptarse al nuevo modelo exportador mediante la introducción de innovaciones tecnológicas y nuevas prácticas de organización y de gestión empresarial, en donde la estrategia orientada a la vinculación y la inserción internacional, tanto de manera unilateral como en el ámbito multilateral y bilateral, ha sido fundamental.

\section{Rubros de mayor dinamismo}

En términos generales, entre 1990 y el año 2004 las exportaciones agropecuarias chilenas experimentaron un fuerte

Cuadro 8

Chile: evolución del comercio exterior agropecuario, 1990-2004

(Millones de dólares)

\begin{tabular}{lcccccccc}
\hline Año & \multicolumn{3}{c}{ Exportaciones agropecuarias } & \multicolumn{3}{c}{ Importaciones agropecuarias } \\
\hline & Total & Agrícolas & Pecuarias & Forestales & Total & Agrícolas & Pecuarias & Forestales \\
\hline 1990 & 2,030 & 1,156 & 67 & 807 & 355 & 296 & 50 & 9 \\
1991 & 2,418 & 1,507 & 73 & 838 & 506 & 407 & 87 & 11 \\
1992 & 2,768 & 1,660 & 69 & 1,039 & 652 & 468 & 170 & 14 \\
1993 & 2,703 & 1,541 & 65 & 1,097 & 684 & 475 & 188 & 21 \\
1994 & 3,275 & 1,721 & 103 & 1,451 & 807 & 606 & 173 & 28 \\
1995 & 4,473 & 2,095 & 113 & 2,266 & 1,043 & 770 & 230 & 43 \\
1996 & 4,170 & 2,510 & 116 & 1,544 & 1,248 & 920 & 271 & 57 \\
1997 & 4,270 & 2,458 & 164 & 1,648 & 1,269 & 916 & 290 & 64 \\
1998 & 4,333 & 2,729 & 169 & 1,435 & 1,262 & 915 & 281 & 65 \\
1999 & 4,720 & 2,738 & 165 & 1,818 & 1,156 & 863 & 241 & 52 \\
2000 & 4,976 & 2,681 & 192 & 2,103 & 1,201 & 845 & 283 & 73 \\
2001 & 4,785 & 2,629 & 266 & 1,891 & 1,133 & 808 & 244 & 80 \\
2002 & 5,185 & 2,878 & 285 & 2,022 & 1,203 & 874 & 246 & 83 \\
2003 & 5,936 & 3,316 & 406 & 2,214 & 1,397 & 980 & 339 & 78 \\
2004 & 7,482 & 3,874 & 600 & 3,008 & 1,606 & 1,111 & 386 & 109 \\
\hline
\end{tabular}

Fuente: ODEPA, 2005a. 
crecimiento al pasar de dos mil millones de dólares a casi 7.5 mil millones de dólares, lo que representa un incremento de $268 \%$ en dicho periodo. Por su parte, las importaciones agropecuarias también mostraron un fuerte dinamismo, al pasar de 355 millones de dólares a 1,600 millones de dólares, con un incremento de $350 \%$ en el mismo periodo (cuadro 8).

Dentro de las exportaciones, la fruticultura, las actividades forestales, los productos pecuarios y la agroindustria se han adecuado mejor a las reformas y ajustes en el sector. En este periodo las frutas ampliaron sus mercados gracias a su temporalidad en relación con los mercados del hemisferio norte; entre los productos más importantes están las uvas, manzanas, peras y kiwis, los cuales componen el grueso de la oferta. No obstante, la misma presión de las exportaciones frutícolas chilenas, que se convirtieron en las más im- portantes del hemisferio sur (actualmente representan $45 \%$ de las exportaciones de uvas, manzanas y peras de la región), junto con el errático comportamiento de algunos mercados que presentaban un gran potencial y con el surgimiento de nuevos competidores, han debilitado su crecimiento y afectado su rentabilidad.

Respecto a las exportaciones agroindustriales, también aumentaron de manera importante. Sobresalen en este rubro productos como las pasas, ciruelas, manzana y peras deshidratadas, conservas de duraznos y jugo de manzana. Otros productos que han surgido con un gran potencial de crecimiento son el concentrado de tomate, pimiento deshidratado y la cebada malteada.

Las exportaciones forestales, por su parte, cuya base son básicamente las plantaciones de pino y eucalipto, absorbieron alrededor de $40 \%$ de las exportaciones

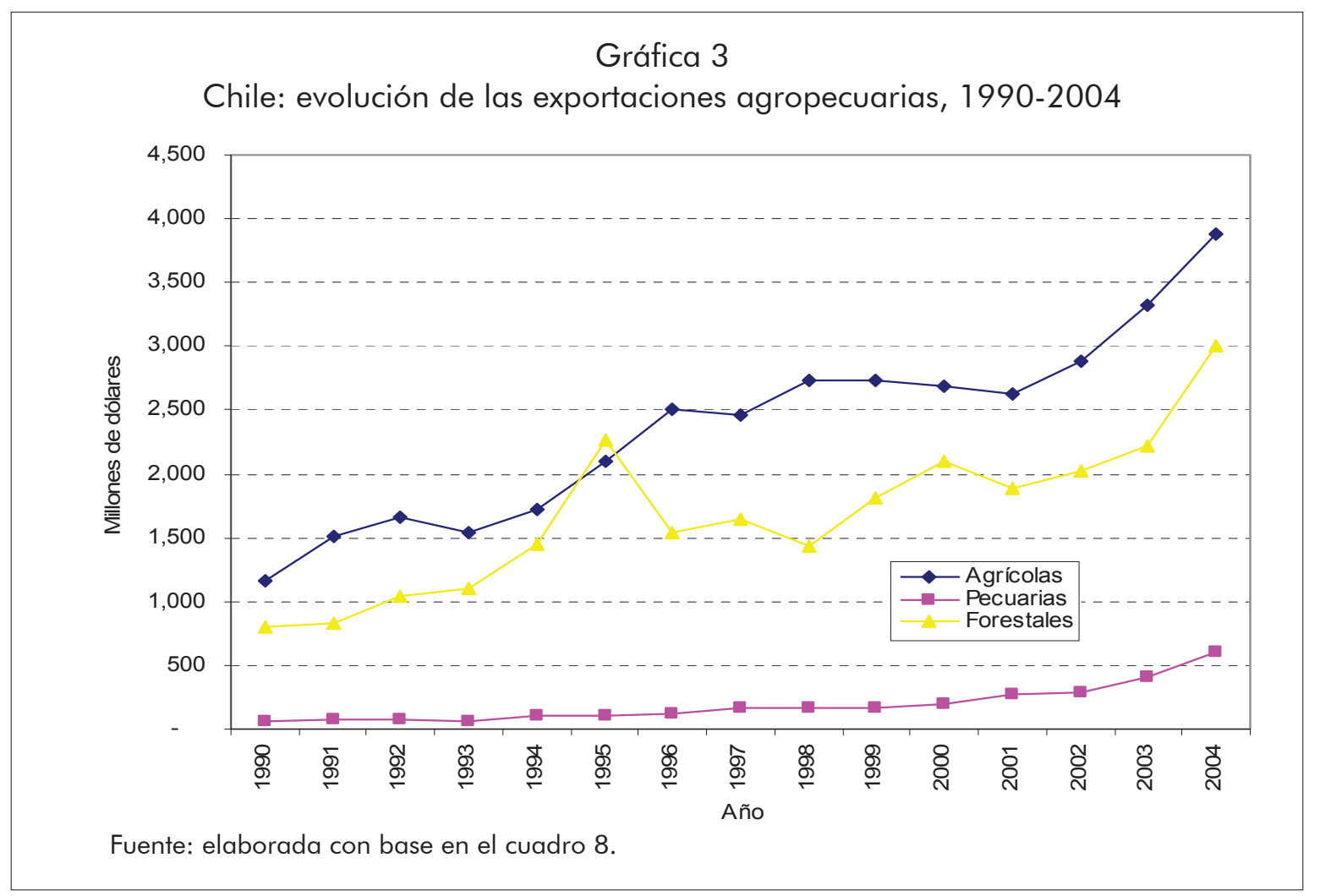


agropecuarias en 2004. La celulosa, cuyos precios internacionales se duplicaron a mediados de los noventa, y la madera aserrada, constituyen sus principales componentes (gráfica 3).

Vista en perspectiva, la estructura de las exportaciones se ha vuelto más equilibrada tanto en su composición por grandes grupos como en su diversificación en productos y mercados. Todos estos cambios se deben a una creciente participación de la inversión privada en el campo chileno, pero sobre todo a la expansión de las trasnacionales en el territorio de Chile.

También es interesante subrayar que en los subsectores agrícola y forestal, que en conjunto representan cerca de $92 \%$ de las exportaciones agropecuarias y que de alguna forma constituyen los símbolos exitosos del modelo exportador chileno, el Estado ejerció un papel fundamental en su impulso inicial. En el primero de ellos mediante el Plan Frutícola puesto en marcha a finales de los sesenta, mientras que en el segundo a partir de un programa de subsidio a las plantaciones forestales iniciado en 1976, el cual había alcanzado un apoyo acumulado del gobierno de 160 millones de dólares.

Del mismo modo, los programas de fomento a las exportaciones no tradicionales le dieron un impulso importante a varios productos agroindustriales. Las nuevas oportunidades del mercado internacional y las políticas de apertura y privatizaciones permitieron que la inversión privada fluyera a estos rubros, obligando a los productores chilenos a buscar constantemente nuevos productos y mercados, mejorando la calidad de sus productos y la eficiencia en toda la cadena agroexportadora con el fin de no perder competitividad.

\section{Rubros de menor dinamismo}

Los cereales y las leguminosas han tenido que enfrentar los mayores efectos de la apertura y desregulación del sector. En términos generales, son los que han mostrado un menor ritmo de crecimiento y los que se generan precisamente en las zonas con menor flexibilidad de los recursos para acceder a una reconversión de la producción. Aun así, importancia de la producción de la pequeña agricultura es relevante.

Chile había sido tradicionalmente un importador de trigo, maíz, arroz, leche en polvo, azúcar y aceite, entre otros. Sin embargo, entre 1974 y 1983, en el contexto de la apertura de la economía y de la tendencia descendente de los precios internacionales, las importaciones se mantuvieron sin mayores cambios. Como se expuso al analizar los cambios en la política agrícola, las medidas adoptadas para atenuar los efectos de la crisis a partir de 1983 incentivaron la producción, alcanzándose en el caso del trigo niveles cercanos a la autosuficiencia. Los precios internacionales del cereal, que experimentaron un alza, ayudaron en este sentido, recuperándose también algunos cultivos industriales como la remolacha. Fue así como entre 1984 y 1990 las importaciones agropecuarias descendieron hasta una tasa de $9 \%$ anual.

Fue a partir de 1990 cuando las importaciones agropecuarias recuperaron su dinamismo, al crecer nuevamente a tasas anuales de 15\%. Productos tradicionalmente importados como el trigo alcanzaron un nivel récord en los volúmenes de importación para mediados de los noventa. A esto se sumó la entrada de carne de bovino, particularmente de Argentina, la cual se incrementó en ocho veces su volumen de importación durante la década de los noventa. Similar situación se observó en arroz y maíz (gráfica 4).

MÉXICO YLACUENCADELPACÍFICO vol. 9, núm. 27 / enero-diciembre de 2006 


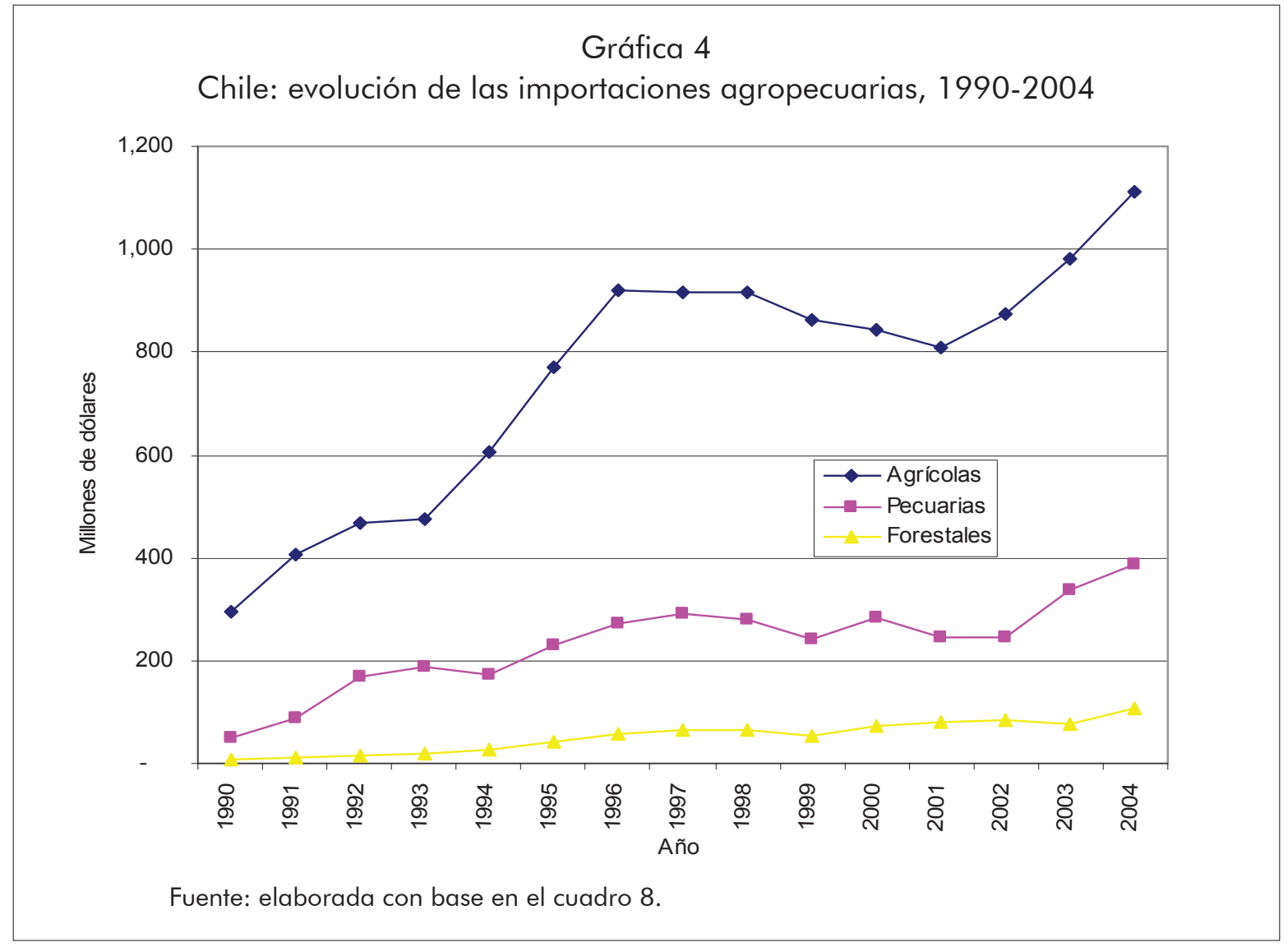

En el subsector pecuario se han consolidado las fuertemente integradas cadenas agroindustriales de cerdo y aves. En carne de bovino, la presión de la oferta argentina ha obligado a mejorar la calidad de las praderas y la productividad de los procesos de producción. En el caso de los productos lácteos, la presencia de empresas trasnacionales que controlan la cadena, aunada a la mayor demanda del mercado interno, ha venido a fortalecer su capacidad competitiva. Sin embargo, se han visto sometidos a una fuerte y constante exigencia en cuanto a calidad y productividad para competir con éxito con la oferta del exterior.

En resumen, el modelo exportador chileno, con todas sus ventajas y desafíos, se ha venido consolidando cada vez más. El histórico papel de un Estado promotor y regulador en los subsectores frutícola, forestal y agroindustrial, los cuales se han caracterizado por su fuerte dinamismo, resultó determinante en su impulso inicial. Las políticas aplicadas en materia de aranceles y de tipo de cambio han apoyado de manera fundamental al modelo exportador. Pero también las ventajas comparativas, la desregulación del comercio exterior y un ambiente propicio para impulsar la inversión privada y gestión empresarial, han favorecido una exitosa inserción del sector agropecuario en el mercado internacional.

\section{Conclusiones}

Excepto el periodo 1981-1983, cuando las condiciones adversas de los mercados 
externos actuaron en contra del sector, en términos generales la agricultura chilena se vio beneficiada con la apertura comercial y con otras medidas desregulatorias, volviendo más funcionales y flexibles los mercados y los factores de producción. Es importante señalar que a partir de 1984 el Estado tuvo una activa participación para contrarrestar el impacto de las fluctuaciones del mercado internacional sobre la agricultura chilena mediante diversos mecanismos, entre ellos el restablecimiento de las bandas de precios, una intervención mínima en la comercialización de productos básicos y la reducción de aranceles. Además, se fomentaron las exportaciones no tradicionales y se impulsó la infraestructura de riego. Esto permitió la recuperación del crecimiento de la producción agropecuaria.

En otras palabras, el tradicional papel de un Estado promotor y regulador en los subsectores frutícola, forestal y agroindustrial, los cuales se han caracterizado por su fuerte dinamismo, resultó determinante en su impulso inicial. Sin embargo, las políticas aplicadas posteriormente en materia de aranceles y de vinculación con el exterior mediante acuerdos comerciales con diversos países de América, Europa y Asia vinieron a apoyar de manera fundamental al modelo exportador chileno. Además, las ventajas comparativas que le confiere su posición geográfica respecto a otros países y un ambiente propicio para impulsar la inversión privada y la gestión empresarial, han favorecido una exitosa inserción del sector agropecuario chileno en el mercado internacional.

Los sectores que se vieron más favorecidos con la desregulación y liberalización de la agricultura chilena fueron principalmente las empresas exportadoras de frutas como manzanas, uvas y peras; la industria forestal; y la agroindustria, particularmente la relacionada con el procesamiento de productos como azúcar, cebada, leche, arroz, uva, carne de cerdo y de aves, jugos y pastas. Lo que significa que en Chile se ha dado una significativa inserción en los mercados internacionales por parte de los grandes y medianos productores agropecuarios, principalmente de las regiones irrigadas y de aquellas regiones agrícolas con una adecuada capacidad tecnológica y de gestión.

No obstante, a partir de 1990, procurando mantener los rasgos esenciales del modelo, se planteó la necesidad de una mayor equidad como condición indispensable para el desarrollo integral del campo chileno, puesto que la misma apertura y reforma estructural del sector agropecuario habían generado una marcada concentración y exclusión en el medio rural. Fue así como la política agrícola puso un énfasis especial en el fortalecimiento de la ruralidad, en reconocimiento a la heterogeneidad de los agentes productivos, planteándose como uno de los principales objetivos la inserción de los pequeños productores en los mercados nacional e internacional mediante diversos instrumentos que incluyeron el subsidio al riego y la fertilización, así como el impulso a las organizaciones de productores.

En este contexto, los grandes y modernos productores empresariales se han adecuado satisfactoriamente a las reformas y ajustes y a las nuevas condiciones de apertura, y se incorporan con mayor dinamismo en el mercado internacional con base en adecuados niveles de gestión y tecnología. Por otro lado, está el pequeño productor con potencial agropecuario que ha recibido apoyo en asistencia técnica, gestión, comercialización y financiamiento por parte del Estado para mantenerse en el mercado.

Para finales de los noventa y principios de la década reciente, se observa que la agricultura chilena experimentó un 
menor dinamismo básicamente como consecuencia del errático comportamiento de los mercados agrícolas internacionales, lo cual ha debilitado el crecimiento y afectado la rentabilidad de la producción agrícola. Esto significa que si bien la agricultura chilena ha logrado avances importantes en cuanto a productividad y competitividad, también es cierto que se ha vuelto mucho más vulnerable a las fluctuaciones de los mercados agrícolas internacionales de lo que anteriormente era. mp

\section{Notas}

1. Este organismo surgió en 1986 y está formado por Argentina, Australia, Bolivia, Brasil, Canadá, Chile, Colombia, Costa Rica, Filipinas, Guatemala, Indonesia, Malasia, Nueva Zelanda, Paraguay, Sudáfrica, Tailandia y Uruguay.

2. Con base en un decreto publicado en el Diario Oficial de la República de Chile el 17 de septiembre de 2003.

3. Actualmente la superficie agrícola de riego asciende a 1.8 millones de hectáreas, que representan tres cuartas partes de la superficie agrícola sembrada.

\section{Referencias bibliográficas}

Ariztia de Castro, Ricardo (2003) Desafíos de la globalización para la agricultura de Chile, octubre, Santiago de Chile.

Canales Cerón, Alejandro (1996) "La modernización del agro chileno en los ochenta", Agricultura y desarrollo regional en la Cuenca del Pacífico, Aportes de la Universidad de Colima, vol. 7, núm. 11 , México.

Coeymans, Juan Eduardo, y Yair Mundlak (1993) "Chilean Agriculture in a Changing Economic Environment", The Bias against Agriculture, Trade and Macroeconomic Policies in Developing Countries. San Francisco: International Center for Economic Growth/The International Food Policy Research Institute.

Comisión Económica para América Latina y el Caribe (CEPAL) (1998) Agroindustria y pequeña agricultura: vínculos, potencialidades y oportunidades comerciales. Santiago de Chile: FAO.

Cox, Maximiliano (1983) La agricultura chilena, 19741982, Santiago de Chile.

_ (1993) La pequeña agricultura chilena: condi- ciones actuales y perspectivas. Chile: Desarrollo Campesino.

Dubreucq, Anne (1994) "Los cambios agrarios en Chile bajo Pinochet, una nueva geografía económica", Agriculturas y campesinados de América Latina. Mutaciones y recomposiciones. México: Fondo de Cultura Económica.

Errázuriz, Luis Felipe, y Eugenia Muchnik (1996) "Visión crítica de la agricultura chilena y sus políticas", Documento de trabajo, núm. 245, marzo. Santiago de Chile: Centro de Estudios Públicos.

French-Davies, R., y O. Rosales (1998) Chile: crecimiento, empleo y equidad. Chile: CEPAL.

Kay, Cristóbal (1996) "Globalización, agricultura tradicional y reconversión en Chile", Comercio Exterior, agosto, México.

Muchnik, Eugenia (1997) Subsidios y ayudas al sector agroalimentario chileno: integración y competitividad, LC/R 1724, Unidad de Desarrollo Agrícola, CEPAL.

Muñoz, Óscar, y Hugo Ortega (1994) "La agricultura chilena y la política económica, 1974-1988", Modernización y estancamiento. La agricultura latinoamericana en los años noventa. México: Fondo de Cultura Económica.

Oficina de Estudios y Políticas Agrarias (ODEPA) (2005a) Compendio estadístico silvoagropecuario, 1990 2004. Santiago de Chile: Ministerio de Agricultura.

(2005b) Panorama de la agricultura chilena, diciembre. Santiago de Chile: Ministerio de Agricultura.

_ (2006) Inserción de la agricultura chilena en los mercados internacionales. Santiago de Chile: Ministerio de Agricultura.

Palma Arancibia, Cristian (1993) La política agrícola en la apertura de la economía: El caso de Chile. Santiago de Chile: Organización de las Naciones Unidas/Oficina Regional de la FAO para América Latina y El Caribe.

Portilla R., Belfor (2000) La política agrícola en Chile: lecciones de tres décadas. Santiago de Chile: Comisión Económica para América Latina y el Caribe/Organización de las Naciones Unidas.

Presidencia de la República (2003) Diario Oficial de la República de Chile, 17 de septiembre, Santiago de Chile.

Valdés, Alberto (1995) "Critical Issues in Sequencing of Reforms: Lessons of Experience from Early Reformers", Agriculture in Liberalizing Economies: Changing Roles for Governments. Proceedings of the Fourteenth Agricultural Sector Symposium. Washington, DC: Banco Mundial.

Venezian, Eduardo, y Eugenia Muchnik (1995) "Learning from Experience of Chile", Agricultural Research in an Era of Adjustment Policies, Institutions and Progress. Washington, DC: Economic Development Institute of The World Bank/International Service for National Agricultural Research. 